\title{
La influencia del sistema meta en traducción: el doblaje de Los Picapiedra al español neutro
}

\author{
Livia Cristina García Aguiar / Rocío García JimÉnEZ \\ Universidad de Málaga \\ liviagaguiar@gmail.com / rogarcia@uma.es
}

Recibido: 16 de junio de 2010

Aceptado: 15 de diciembre de 2010

\section{RESUMEN}

Durante los años cuarenta, surgió una variedad lingüística del español que se empleaba de manera exclusiva en los doblajes de películas y series televisivas, fundamentalmente de producción estadounidense, con la intención de realizar un doblaje único para todo el mercado hispanohablante: el español neutro. La serie de dibujos animados The Flintstones (Los Picapiedra), creada en la década de los sesenta por la productora Hanna Barbera, fue doblada a este español neutro. Mediante el análisis de los rasgos del doblaje de la primera temporada completa de Los Picapiedra, intentaremos demostrar que a pesar de que el objetivo del español neutro consistía, precisamente, en crear una variedad del español lo más estandarizada posible, creemos que toda traducción se ve fuertemente influenciada por la cultura meta que la acoge.

Palabras clave: Traducción audiovisual, doblaje, español neutro.

The Influence of the Meta-System in Translation. The Dubbing of The Flintstones into Neutral Spanish

\begin{abstract}
During the 40's, it appeared a Spanish linguistic variety, called neutral Spanish, which was used exclusively in the dubbings of films and television series (most of them American). By using this standard linguistic variety, one dubbed soundtrack will cover all the Spanish-speaking market. The cartoon television series The Flintstones, created by Hanna Barbera Productions in the sixties, was dubbed to neutral Spanish. In this work, our objective is to examine the features of the dubbing of The Flintstones' complete first season and to show that, although the aim of neutral Spanish was to create a standard linguistic variety, every translation is strongly influenced by the meta-system to which it belongs.
\end{abstract}

Key Words: Audiovisual Translation, Dubbing, Neutral Spanish. 
Sumario: 1. Introducción metodológica. 1.1. Introducción al modelo de análisis descriptivo de G. Toury. 2. El español neutro. 3. Análisis del corpus textual. 3.1. Características fonéticas. 3.2. Características morfosintácticas. 3.3. Características léxicas. 4. Conclusiones.

\section{Introducción metodológica}

Al inicio de la década de los sesenta, la productora estadounidense Hanna Barbera creó la serie televisiva de dibujos animados The Flintstones, conocida en español con el título de Los Picapiedra ${ }^{1}$. La característica principal del doblaje español fue que se realizó al español neutro, variedad lingüística estandarizada que se comenzó a usar con la intención de realizar un doblaje único para todo el mercado hispanohablante. Esto suponía la eliminación de cualquier tipo de modismo con objeto de conseguir un acento neutral entendible por cualquier telespectador del ámbito hispanohablante. Por consiguiente, se pretendía crear una traducción "esterilizada" que no dejara traslucir la variedad del español hablado por sus traductores y dobladores.

Mediante el análisis de los rasgos del doblaje de la primera temporada completa de Los Picapiedra, intentaremos demostrar que a pesar de que el objetivo del español neutro consistía en crear una variedad del español lo más estandarizada posible, toda traducción está influenciada por la cultura meta en la que está inmersa.

La primera temporada de Los Picapiedra se compone de los siguientes 28 episodios $^{2}$ :

El Pica Avión (E1); Noche de parranda (E2); La piscina (E3); No se busca ayuda (E4); La doble personalidad (E5); El monstruo de la brea (E6); Las niñeras (E7); En las carreras (E8); El anillo de compromiso (E9); Artistas famosos (E10); El campeón de golf (E11); El boleto de lotería (E12); El restaurán (E13); El intruso (E14); La noche de las chicas (E15); Las clases de baile (E16); El gran robo (E17); Los cazadores (E18); El piano caliente (E19); El hipnotista (E20); Carta de amor en las rocas (E21); El magnate (E22); Los astrolocos (E23); Largo fin de semana (E24); En la masa (E25); El buen Scout (E26); Los Picapiedra se alquilan cuartos (E27); Pedro Picapiedra. Antes y después (E28).

Hemos de señalar que no se trata de un estudio de carácter analítico y comparativo entre texto origen y texto meta, sino que nos centramos especialmente en el análisis del texto meta. Para ello, seguimos la metodología de los Estudios Descriptivos (Toury 1995). En este sentido, nos basamos en la idea de que las traducciones no son productos aislados, sino que se integran plenamente en el sistema cultural de la lengua meta. Además, uno de los objetivos de este trabajo consiste en demostrar la fuerte influencia que la cultura meta ejerce en una traducción. Por tanto, pretendemos

\footnotetext{
${ }^{1}$ Con el objeto de agilizar la lectura, a partir de ahora nos referiremos a la serie analizada mediante el título en español.

2 A cada episodio le hemos asignado una clave con objeto de facilitar la localización de los ejemplos expuestos.
} 
hacer hincapié en el hecho de que el análisis de traducciones no debe ser enfocado únicamente desde un punto de vista lingüístico, tal y como afirma I. Even-Zohar (1979).

G. Toury, a partir de la Teoría Polisistémica de I. Even-Zohar (1979), establecerá los principios básicos de los estudios contemporáneos sobre la traducción, basados en la descripción y en la reformulación de los conceptos de equivalencia y norma.

\subsection{Introducción al modelo de análisis descriptivo de G. Toury}

G. Toury (1995) argumenta que, debido a que las traducciones influyen en el desarrollo de un sistema supliendo las faltas del mismo con nuevas ideas y conceptos, los análisis de las traducciones deben hacerse teniendo en cuenta el papel que estas juegan dentro del sistema en el que han sido incluidas, y por tanto, deben ser estudiadas de acuerdo con las normas que rigen tal sistema. Dichas normas se clasifican en tres tipos, que se relacionan entre sí y dependen las unas de las otras:

La norma inicial es la que va a hacer que el traductor decida realizar una traducción orientada al polo origen o al polo meta. De esta manera, si el traductor se decanta por la primera posibilidad se tendrá que adherir a las normas activas en el sistema origen; si por el contrario elige la segunda, entonces deberá actuar conforme a las normas activas establecidas en el sistema meta o en el sector de ese sistema en el que se presente la traducción.

En segundo lugar, se sitúan las normas preliminares, las cuales se aplican a aquella información relacionada con la política de traducción que se ha seguido y con la información que determina si la traducción se trata de una traducción directa o indirecta.

Por último, encontramos las normas operacionales, que son aquellas que dirigen las decisiones que se toman durante el acto de traducción. Además, Toury añade que estas normas afectan a la matriz del texto, es decir, a la forma de distribuir el material lingüístico, así como a la textura y a la formulación verbal del texto. También gobiernan, directa o indirectamente, las relaciones que se establecen entre el texto meta y el texto origen, es decir, qué es más previsible que permanezca invariable en la traducción y qué cambiará.

Dentro de las normas operacionales, se encuentran las normas matriciales, que son las que controlan si la traducción está completa o no, es decir, si el texto meta presenta omisiones con respecto al texto origen. También estudian la distribución del contenido del texto meta con respecto al texto origen (cómo se han ubicado los contenidos y si han cambiado con respecto al original), así como la segmentación textual.

Las normas operacionales se componen, además, de las normas matriciales y de las normas lingüístico-textuales, que son las que estudian el material con el que se formula el texto meta. 


\section{El español neutro}

Existen numerosas definiciones de esta variante del español. A. Ávila (1997: 46) afirma que se trata de una variante que consiste "en respetar los seseos iberoamericanos sin exagerar el acento propio del doblador o del país donde se realizara el doblaje".

No solo se han dado numerosas definiciones del español neutro, sino que también el concepto goza de muchas denominaciones. I. García Izquierdo ofrece algunos de los diferentes nombres con los que también se conoce al español neutro, como español internacional, español común, castellano general o español estándar, entre otros (García Izquierdo 2006: 152-153).

Con respecto a los orígenes del español neutro, en 1944 la Metro Goldwyn Mayer reunió en México a un grupo de actores para grabar en Nueva York la versión española de los filmes estadounidenses. El objetivo primordial del doblaje consistía en que el español empleado fuera, según X. Castro (1996), "un español inteligible para cualquier hispanohablante; libre de localismos y lo más neutro posible".

Los actores contratados en un principio para esta tarea fueron los actores de radio, ya que se consideró que estos poseían ese "acento neutro tan deseado". No obstante, las reacciones a estos doblajes no fueron precisamente positivas, ya que el gobierno mexicano consideró que suponían un peligro para la industria cinematográfica nacional. Los doblajes al español se prohibieron y dos años más tarde, la mayoría de los actores regresaron de Nueva York. Sin embargo, lo que sí se creó fue una industria de doblaje propia y se comenzaron a doblar numerosas series televisivas. Es preciso mencionar que estas series, junto con las películas de dibujos animados que se doblaron para Walt Disney, se emitieron en España y fueron las que realmente dieron a conocer de forma general el español neutro, que, en realidad, se trataba en un principio de un español mexicano neutro. Sin embargo, A. Guevara (2003: 54) comenta que durante esta primera etapa los iniciadores del español neutro:

fueron los directores de doblaje bajo las indicaciones de productores que sondeaban al público de las diferentes regiones. La generalización de los públicos y los avances tecnológicos fueron puliendo el acento que cada vez se encontraba con más exigencias pero que también contaba con mayor presupuesto.

\section{Análisis del corpus textual}

A continuación presentaremos los resultados del análisis de nuestro corpus, para el que hemos seguido las normas propuestas por Toury (1995), ya que consideramos que el análisis de las traducciones debe hacerse desde un punto de vista descriptivo puesto que no debemos pasar por alto que son hechos de carácter histórico y cultural que ejercen una función en el sistema meta en el que se incluyen.

Según la norma inicial, la traducción de la primera temporada completa de Los Picapiedra se caracteriza por estar orientada al polo meta, ya que se ha acogido a las normas de la cultura y la lengua metas. 
Con respecto a las normas preliminares, se trata de una traducción directa. Además, las normas preliminares que han definido la política de traducción en la lengua meta han considerado este texto como un producto audiovisual.

Por último, dentro de las normas operacionales, son las normas lingüístico-textuales las que determinan que la traducción presente una serie de rasgos fonéticos, morfosintácticos y léxicos particulares propios del sistema meta, que analizamos a continuación.

\subsection{Características fonéticas}

M. Vaquero de Ramírez (1998a: 10) señala que el seseo es el único rasgo fonológico general del español de América. En el doblaje de Los Picapiedra que hemos analizado el seseo es una constante.

Con respecto al vocalismo, podemos señalar que en nuestro corpus se dan ciertas vacilaciones en la diptongación de algunos sustantivos y adjetivos. Así, por ejemplo, encontramos el caso de dinosauro [E1], frente al español estándar dinosaurio. Asimismo, los ejemplos calientito [E6] y suenaremos [E16] nos muestran otro tipo de alternancia en la diptongación.

Siguiendo con los rasgos de pronunciación, en nuestro corpus encontramos que se da una solución niveladora de las palatales sonoras, lateral y fricativa $/ \lambda / \mathrm{y} / \mathrm{y} /$, con pérdida de la lateral palatal, dando como resultado el yeísmo.

\subsection{Características morfosintácticas ${ }^{3}$}

Lo primero que podemos destacar es que en nuestro corpus la forma de tratamiento para la referencia a la segunda persona del plural es siempre mediante ustedes, tanto en el trato de cortesía como en situaciones de confianza. Se trata de uno de los pocos fenómenos comunes a toda Hispanoamérica, y también presente en Andalucía Occidental.

En segundo lugar, encontramos un gran número de adjetivos que desempeñan la función del adverbio. Por ejemplo, el caso de qué bueno [E1 y E7], lo lamento infinito [E21], jugar rudo [E22] o quedaría igual de malo [E27].

Por otra parte, observamos que es frecuente, en determinadas estructuras, la elisión del artículo, como sucede en los siguientes ejemplos:

Como si fueras pájaro [E1], como suela de zapato [E7], eres gallina [E9], le di vuelta [E13, ] todo mundo [E15, E18], como si fueras hombre [E18], pareces perro [E20], o temblar como gelatina [E21].

\footnotetext{
${ }^{3}$ Toda la información referida a la distribución de los fenómenos señalados por el dominio hispánico ha sido extraída de la edición disponible en la web del Diccionario Panhispánico de Dudas de la Real Academia Española de la Lengua.
} 
También el uso de los adverbios acá y allá, predominante en las variedades americanas, está muy presente en nuestro corpus: vienen hacia acá [E1], ¿qué es lo que haces tú allá? [E10].

Asimismo, encontramos ejemplos del uso de la locución adverbial entre más, que pertenece a la norma culta general en México y el área centroamericana, como sucede en entre más plata tengas, más amigos tendrás [E4].

Por otra parte, podemos destacar el empleo de la locución adverbial qué tanto equivalente a cuán(to) o a cómo de, que puede aparecer en oraciones interrogativas o exclamativas, en el ejemplo: qué tanto hace el coronel con mi marido [E15]. Era normal en el español medieval y clásico, y hoy pervive en amplias zonas de América.

Otro rasgo característico en nuestro corpus consiste en la supresión de preposiciones, dando lugar a veces a estructuras queístas, tal y como observamos en:

Antes que [E2], darse cuenta que [E5], avise que [E5], en caso que [E8], dar cuenta que [E12], avisarle que [E13] y hacer cuenta que [E18].

Por último, los ejemplos de jugar boliche/golf/billar/baraja/polo [E5/E4/E8/E15/E22] son típicos del habla coloquial de amplias zonas de América. Probablemente por calco del inglés, jugar se emplea a menudo como verbo transitivo, esto es, sin que el sustantivo que denota el juego vaya precedido de preposición, además de no llevar artículo.

Con respecto a los pronombres átonos, como es sabido, la pluralidad del complemento indirecto les desparece cuando este pronombre se convierte en se, forma invariable. La marca perdida de pluralidad se recupera en el pronombre de complemento directo, dando como resultado construcciones del tipo se los di, en vez de se lo di (el libro, a ellos). Como señala M. Vaquero de Ramírez (1998b: 22), este tipo de construcciones es de uso general en las Antillas, Colombia, México, Panamá, costa del Perú y Venezuela. Nosotros encontramos el ejemplo de se los ordeno [E22].

El empleo de ciertas formas verbales es uno de los rasgos más peculiares del español neutro. M. Vaquero de Ramírez (1998b: 29) apunta que es más frecuente la aparición de formas simples, frente a las compuestas. Principalmente, esto se refleja en el uso aparente del pretérito indefinido en lugar del pretérito perfecto compuesto. J. Moreno de Alba (2007: 180) comenta que "mientras en el español peninsular la oposición canté/he cantado no se basa en el aspecto [...] en español americano la diferencia estriba precisamente en el aspecto". Hemos recopilado numerosos ejemplos, de entre los que destacan los siguientes:

Pedro, ya llegué [E1], ¿oíste? Ya los localizaron [E2], ¿qué pasó? [E2], ya las recordé [E2] o ipescaste algo? [E14].

A pesar de lo extendido que está el uso del pretérito indefinido frente al uso del pretérito compuesto, M. Vaquero de Ramírez (1998: 29) argumenta que el pretérito indefinido depende "de muchos factores discursivos y no significa que haya desparecido el compuesto". Muestra de ello es que hemos encontrado expresiones de pasado reciente en las que se emplea el pretérito perfecto compuesto, tal y como sucedería en la norma estándar del español peninsular: tal vez la has ignorado [E21], no he vuelto a patinar desde que era un niño [E21]. 
También observamos que, frente a lo que sucede en el español estándar actual, se da una predominancia de formas de futuro simple en lugar del uso de la perífrasis ir+infinitivo, como sucede en: ¿Resultará? [E1], tampoco tú jugarás [E1].

Aunque el uso de la perífrasis haber que+infinitivo es impersonal, es decir, solo se conjuga en tercera persona del singular, en nuestro texto hayamos numerosos ejemplos en los que, si el verbo que le sigue es pronominal, el pronombre aparece en primera persona del plural. No se trata de un uso correcto, pero creemos que es significativo el hecho de que el único ejemplo de esta incorrección que aparece recogido en el Diccionario Panhispánico de Dudas corresponda a un ejemplo mexicano. Encontramos muestras de esta construcción, como:

Hay que quitarnos [E2], no hay que perdernos [E7], habrá que olvidarnos de eso [E8] o hay que irnos [E23].

Del mismo modo, el uso de la perífrasis estar por+infinitivo con el significado de estar a punto de, típico de América, aparece frecuentemente en nuestro corpus: están por lanzar [E23].

La preferencia por el subjuntivo frente al indicativo en algunas construcciones es un hecho constatable en nuestro corpus:

¿Qué se supone que sea? [E2], ¿crees que dé resultado? [E4], ¿crees que podamos ganar? [E10], yo no sé lo que pienses tú [E15], yo los vi jugar en la liga y vieras cómo le pegan a la pelota [E26], qué conmovedor, quisieras llorar [E22].

También podemos destacar el empleo de verbos con un régimen diferente al del español peninsular. Por ejemplo, desaparecer se usa a menudo en el español de América como transitivo, con el sentido causativo de hacer que algo o alguien desaparezca. Este uso convive con la estructura causativa normal. Así, encontramos como yo desapareci tu huevo [E2], frente a Pedro pensará que nos ha hecho desaparecer [E2].

Otro ejemplo lo constituiría el uso pronominal, habitual en el español medieval y clásico, del verbo tardarse con el sentido de emplear demasiado tiempo en hacer algo, como en los ejemplos: no me tardo ni un minuto en ponérmelo [E2] y se tardó mucho en prepararme un ligero refrigerio [E25].

El verbo obsequiar puede construirse con un complemento directo de persona y un complemento introducido por con que expresa el regalo, o con un complemento directo que expresa el regalo y un complemento indirecto que expresa la persona que lo recibe, construcción esta última claramente mayoritaria en el español de América: se las obsequié a Betty y a Pablo [E4] o ustedes me van a obsequiar 500 dólares [E9].

Por otra parte, aparecerse se puede usar como verbo pronominal, especialmente en el español americano, como ocurre en nuestro texto: Betty nunca se aparece [E12].

En el español de América, cuando no hay complemento indirecto, es frecuente usar el verbo robar en forma pronominal: saca la escalera y ; a robarse este billete! [E12].

Asimismo, apurarse se emplea con el significado de apremiar o dar prisa: apúrate, Benito [E17]. 
Otro fenómeno característico de la variedad del español hablado en América, según M. Vaquero de Ramírez (1998: 31), son las estructuras anglicadas, es decir, aquellos usos verbales motivados por la situación de lengua de contacto en la que se encuentran algunas lenguas hispanoamericanas. Además, suponemos que el español neutro de los doblajes va estar bastante influido por este fenómeno, ya que al ser empleado en este caso como lengua meta y traducción del inglés, va a contar con numerosas estructuras de este tipo. Hemos encontrado casos de convergencia sintáctica, definida como el "aumento de la frecuencia de uso de una estructura alterna de la lengua por imitación de otra lengua" (Morales 1992: 339). Partimos de la relación de estructuras anglicadas que M. Vaquero de Ramírez (1998: 32) analiza:

- Preferencia por el indicativo frente al subjuntivo en casos de alternancia:

Ojalá el nuestro no está cruzado [E8], antes de que comienza [E10], ojalá ganas [E12], después de que nace [E25], después de que ustedes salieron [E27], empiecen cuando están listas [E27].

- Asimismo, encontramos una relativa frecuencia de construcciones pasivas en nuestro corpus:

Pedro y Pablo fueron ascendidos a la caballería [E23], serán transportadas por aire y serán llevadas a cocinas individuales [E25].

- También nos encontramos con algunos casos de interferencia sintáctica o transferencia, definida como "el desvío de la norma estándar cuando se copia una estructura de otra lengua" (Morales 1992: 340). Véanse los casos en lo que el subordinante que se omite:

Te juro los compré [E3, ] que sé ciertas personas me pidieron prestadas [E3], pero ¿cree usted yo sirva? [E6].

- U otros ejemplos de calco sintáctico como:

Mañana en la mañana [E4], le pedí su mano [E9], ser un doctor [E10], dinero es dinero [E17], hoy en la tarde [E21]; así como los numerosos casos en lo que se utiliza la preposición por para indicar la duración de un proceso, como por ejemplo: por un segundo [E3], por más de cinco minutos [E4] o por veintiséis semanas [E10].

- Por último, hemos encontrado algunos casos en los que se emplea el verbo ser en lugar de estar, como consecuencia de la traducción literal del verbo to be: la voz es un poco ronca debido al viaje en avión [E25].

\subsection{Características léxicas}

Por último, vamos a tratar la cuestión del léxico utilizado en el doblaje de Los Picapiedra. Nos encontramos ante un léxico libre, en su mayor parte, de localismos, modernismos y vulgarismos, lo que favorece que el lenguaje empleado pueda sonar artificial e incluso arcaico al espectador peninsular. Es cierto que el español neutro de la serie apenas presenta rasgos léxicos propios de Hispanoamérica. En él, por ejemplo, no se encuentran indigenismos ni afronegrismos, a excepción de la voz caribe macana, en referencia a un garrote grueso de madera dura y pesada [E7] o las voces nahua atole [E8] o guachinango [E20]. 
Sin embargo, a pesar de que la intención del doblaje es la de conseguir un lenguaje neutro, sin localismos, no podemos olvidar que la traducción está inmersa en la realidad cultural del sistema meta, en este caso la hispanoamericana, por lo que es inevitable encontrar un cierto número de términos característicos del español de América. Algunos de los casos que hemos recopilado son ${ }^{4}$ :

Aventar. (Col., Hond. y Méx.) Arrojarse (ir violentamente hacia alguien o algo): [el periódico] solo lo avientan los domingos [E1].

Box. (Ec. y Méx.) Boxeo.

Buchaca. (Col., Cuba, Hond. y Méx.) Bolsa de la tronera de la mesa de billar: voy a meter esta bola en la buchaca [E3].

Cantinero. (Cuba y México) En los bares, tabernas y cantinas, hombre encargado de preparar y servir las bebidas.

Clóset. (América) Armario empotrado: ahora lo esconderé donde no lo encuentre. Probaré en el clóset esta vez [E9].

Corretear. (Bolivia, Chile, Honduras, México, Nicaragua y Perú) Correr, perseguir: está usted harto de corretear a la chica [E6].

Cubeta. (Honduras y México) Cubo.

Chango. (México) Mono, simio: se subió a ese árbol como si fuera un chango [E7].

Chocante (Am.) Antipático, fastidioso, presuntuoso: en la cima está el chocante de Rock Hudson con la chica que amas [E6].

Chuza. (México) En el juego del boliche o bolos, lance que consiste en derribar todos los palos de una vez y con solo una bola: toma, tira la bola y haz una chuza [E5].

Empacar. (América) Hacer el equipaje: a casa todo el mundo, empaquen todas las cosas [E6].

Enlistar. (México) Alistar, reclutar: después de enlistarse en el ejército [E23].

Jalón. (Canarias y América) Tirón: ¿dónde querías que estuviera con ese jalón que diste? [E7].

Macanudo. (Coloquial en América) Bueno, magnífico, extraordinario, excelente, en sentido material y moral: qué pelea más macanuda [E7].

Manejar. (América) Conducir, guiar el automóvil: pues a ver si te acuerdas que las carreteras se maneja de lado derecho [E17].

Mesera. (América) Camarero de café o restaurante: le preguntaré a la mesera del restorán [E23].

Popote. (México) Pajilla para sorber líquidos: dame una piedracola con un par de popotes [E1].

Recámara. (Colombia, México y Panamá) Dormitorio: podemos salir y escondernos en la recámara [E2].

Regresar. (América) Devolver o restituir algo a su poseedor: voy a regresarte tu pala [E5].

${ }^{4}$ Todas las definiciones han sido tomadas de la edición online del Diccionario de la Real Academia Española de la Lengua. 
Tachuela. (Coloquial en Bolivia, Chile, Cuba, El Salvador y Honduras) Persona de estatura muy baja: permitido, tachuela [E18].

Vacacionar. (América) Pasar las vacaciones: al mismo tiempo que vacacionamos, nos procuramos viandas para nuestra mesa [E18].

Viejo. (Coloquial en América) Se usa como apelativo para dirigirse a la madre o al padre, a la esposa o al esposo, o entre amigos: Pedro, ¿cómo estás, viejo? [E2].

Además, hemos encontrado en nuestro corpus modismos o expresiones idiomáticas pertenecientes al español de América y, más en concreto, al español hablado en México:

Comer ansias. (México) Impacientarse: no comas ansias, Pablo amigo, ya llegamos [E19].

Favor de. (América central, Chile, Colombia, Ecuador, México y República Dominicana) Hágame el favor de: favor de mandarme todos los vestidos que vi la semana pasada [E17].

Ni modo. (Coloquial en México) Se usa para indicar que algo ya no tiene remedio: ¡ni modo! Tendré que hacer otro aparato [E1].

Volarse la barda. (Coloquial en México) Tener un éxito inesperado, conseguir un buen resultado: usted tiene talento [...] Betty, te volaste la barda [E17].

Mención aparte merece la adaptación de dichos y refranes patrimoniales, como se puede observar en los siguientes ejemplos:

Metí la pata hasta el once [E6]; Sangre de atole [E8].

Este último dicho se corresponde con el del español peninsular sangre de horchata. Esto se explica si tenemos en cuenta el significado de la voz nahua atole, que en Honduras y México se emplea para referirse a una bebida caliente de harina de maíz disuelta en agua o leche, a la que se pueden agregar sabores edulcorantes.

Por último, destacamos la presencia de numerosos calcos debido a la influencia del inglés, aunque esto también podría considerarse como una cuestión puramente traductológica, ya que se puede deber a que el traductor o grupo de traductores se haya dejado contaminar por la lengua origen. Estos son los casos hallados:

Iniciar el conteo [E7]; Vigile mi peso [E9]; Los comerciales de la televisión [E9]; Baños de sol [E10]; Té sobre las rocas [E17]; Antes meridiano [E18]; Aplicar una multa [E18].

\section{Conclusiones}

En traducción audiovisual se han estudiado en profundidad el proceso de traducción, las características de los subtipos de traducción que la componen (sobre todo, el doblaje y el subtitulado) y la traducción como producto, donde se han ofrecido varios modelos de análisis. Sin embargo, consideramos que sería necesario profundizar más en este último apartado y en la realización de análisis descriptivos de traducciones audiovisuales entendidas como productos. Estos estudios, además, deberían hacerse desde una perspectiva socio-cultural, ya que los textos audiovisuales contienen una fuerte carga de este tipo. De esta manera, se entenderán mejor las formas de actuación adoptadas por los traductores, las pautas que se han seguido o las estrategias de traducción empleadas. 
Con respecto a los doblajes al español neutro, se caracterizan por ser un tipo de doblaje con el que todos hemos tenido contacto como telespectadores alguna vez y que apenas han sido estudiados. Este tipo de doblaje marcó una etapa en la historia del doblaje español y caracterizó fuertemente a los productos audiovisuales en los que fue empleado. No obstante, aunque el español neutro no se haya vuelto a emplear en el doblaje de películas animadas y series de televisión no quiere decir que haya desaparecido por completo. Actualmente, se está convirtiendo en un lenguaje de especialidad que se usa en las traducciones científico-técnicas. Tampoco podemos considerar que ya no podamos acceder a productos audiovisuales doblados a esta variante del español, ya que la rapidez con la que se mueve el mundo de Internet y de las nuevas tecnologías hace que en la actualidad se puedan encontrar numerosos videojuegos en español neutro.

Por último, en nuestro análisis hemos estudiado los rasgos más significativos que presenta el español neutro en el doblaje de Los Picapiedra. Consideramos que el intento de la variedad por aglutinar todos los giros de la lengua española desde un punto de vista generalizador es bastante efectivo $y$, sin duda, constituye una rica fuente gramatical y léxica para todos los hispanohablantes, además de un gran ejemplo de tolerancia lingüística. Sin embargo, como hemos observado en los apartados morfosintáctico y léxico, abundan rasgos caracterizadores del español hablado en América y, más en concreto, de la variedad de México. Por lo tanto el intento por conseguir una variedad artificial, en el sentido de no ser propia de ninguna variedad regional del español, y válida para todos los hispanohablantes, no surtió todo el efecto deseado.

Consideramos que esto no es más que otra prueba que demuestra la dificultad que presentan las traducciones para existir fuera de su contexto histórico y cultural. Como acabamos de mencionar, aunque la finalidad de la traducción de Los Picapiedra era conseguir un lenguaje neutro que no dejara entrever rasgos lingüísticoculturales propios de ninguna zona de habla hispanoamericana, el hecho de que los traductores y actores de doblaje fueran en su mayor parte mexicanos supuso un escollo en la consecución de este objetivo. Las traducciones son parte del sistema en el que se desarrollan y, por tanto, suceden en el mismo eje espacio-temporal de dicho sistema. Si se analizan detenidamente, proporcionarán información muy valiosa sobre el período histórico y cultural en el que aparecieron por primera vez. Además, constituyen una rica fuente de ejemplos reales que sin duda ayudarán a cimentar el análisis histórico en traducción.

\section{Referencias bibliográficas}

Ávila, A., El doblaje. Madrid: Cátedra 1997.

Ávila, A., La historia del doblaje cinematográfico. Barcelona: CIMS 1998.

Castro, X., «El español neutro» en: VV. AA. (eds.), Congreso Anual de la ATA (Asociación Estadounidense de Traductores). Publicación virtual disponible en http://www.xcastro.com/neutro.html [Consulta: 27/05/2010].

Even Zohar, I., Papers in Historical Poetics. Tel Aviv: Porter Institute 1978. 
Even Zohar, I., «Polysystem Theory», Poetics Today 1 (1979), 287-310.

García Izquierdo, I., «El español neutro y la traducción de los lenguajes de especialidad» Sendebar 17 (2006), 149-168.

Guevara, A., Locución: el entrenador personal. Buenos Aires: Galerna 2003.

Morales, A., "Variación dialectal e influencia lingüística: el español de Puerto Rico», en: Hernández Alonso, C., (ed.), Historia y Presente del Español de América. Valladolid: Junta de Castilla y León, 1992, 333-354.

Moreno de Alba, J., Introducción al español americano. Madrid: Arco Libros 2007.

Toury, G., In Search of a Theory of Translation. Tel Aviv: The Porter Institute for Poetics and Semiotics, Tel Aviv University 1980.

Toury, G., Descriptive Translation Studies and Beyond. Philadelphia/Amsterdam: John Benjamins Publishing 1995.

Vaquero de Ramírez, M., El español de América I. Pronunciación. Madrid: Arco Libros 1998a.

Vaquero de Ramírez, M., El español de América II. Morfonsintaxis y Léxico. Madrid: Arco Libros 1998b. 